\title{
COVID-19 recovery: implications for cancer care clinicians
}

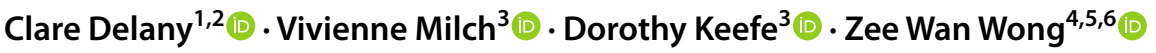

Received: 26 July 2021 / Accepted: 26 September 2021 / Published online: 9 October 2021

(c) The Author(s), under exclusive licence to Springer-Verlag GmbH Germany, part of Springer Nature 2021

\begin{abstract}
The wellbeing of clinicians delivering cancer care needs to be considered and included in recovery roadmaps from the COVID-19 pandemic. In this paper, we refer to a report undertaken by Cancer Australia to review and reflect on the impact of COVID-19 in the delivery of cancer care. The report focused on post COVID-19 recovery and asked 3 questions: What changed? What has been the impact of that change? And how can high-value changes be embedded or enhanced? We suggest the same three questions should also be asked of cancer care clinicians. Using the three Cancer Australia questions, we draw from clinicians' insights collected through the Victorian COVID-19 Cancer Network (VCCN) and from the wider health professional literature. We summarise key features of the COVID-19 experience for cancer care clinicians, highlighting moral distress, fatigue and disrupted practice. We then discuss how pandemic-related ethical values might guide health leaders and administrators to balance support for clinician wellbeing with ongoing delivery of cancer care for patients.
\end{abstract}

Keywords Cancer care clinicians $\cdot$ COVID-19 $\cdot$ Recovery $\cdot$ Ethics

\section{Introduction}

The COVID-19 pandemic has forced a paradigm change in cancer care delivery. New models of care have been developed [1], existing ones strengthened [2] and strategies to mitigate risks of care disruptions have been established [3]. Cancer Australia recently reviewed and reflected upon these

Clare Delany

c.delany@unimelb.edu.au

Vivienne Milch

Vivienne.milch@canceraustralia.gov.au

Dorothy Keefe

Dorothy.keefe@canceraustralia.gov.au

Zee Wan Wong

zee.wong@monash.edu

1 Peter MacCallum Cancer Centre, 305 Grattan st Parkville, Melbourne 3010, Australia

2 Department of Medical Education, Melbourne Medical School, The University of Melbourne, Victoria, Australia

3 Cancer Australia, Surry Hills, NSW, Australia

4 Peninsula Clinical School, Monash University, Clayton, VIC, Australia

5 Southern Melbourne Integrated Cancer Service, Melbourne, Australia

6 Oncology Unit, Peninsula Health, Melbourne, Australia changes, focusing on COVID-19 recovery for cancer care delivery[4]. The review examined 3 questions:

1. What changed?

2. What has been the impact of that change?

3. How can high-value changes be embedded or enhanced?

In this paper, we apply the same three questions to probe the experiences of and review implications for frontline cancer care clinicians. We summarise key features of the COVID-19 experience for cancer care clinicians and suggest how their wellbeing might be considered as a component of COVID-19 cancer care recovery by health leaders and funders in Australia and beyond. In particular we highlight (Table 1) the need to identify and balance several ethically important values which support both patient care and clinician wellbeing. Our summary draws from monthly discussions (May 2020-July 2021) of the Victorian COVID-19 Cancer Network (VCCN) [5] and associated publications $[1,2,4]$. The VCCN is an Australian statewide clinical network, established in March 2020, supported by the Victorian Government, to provide an online forum enabling clinical and ethics discussions, data sharing and expert consensus to pro-actively address COVID-19-related challenges in cancer care (1). 
Table 1 Guiding ethical values for public safety and wellbeing in a pandemic situation applied to clinicians providing healthcare (adapted from [16])

\begin{tabular}{|c|c|}
\hline Pandemic-specific ethical values & Applied to clinician wellbeing \\
\hline 1 Duty to provide care & $\begin{array}{l}\text { As an inherent part of their duty to provide a safe workplace, health institutions have a duty to promote clini- } \\
\text { cian well-being, visible within strategic visions of high quality care and associated operational policies }\end{array}$ \\
\hline 2 Protection from harm & $\begin{array}{l}\text { Protecting clinicians from harm (psychological, physical, emotional and moral) is foundational to the duty of } \\
\text { care of health service employers and leaders. This will require a range of staff services developed in close } \\
\text { consultation with health staff (and involve attention given to mental health services, staff rosters, safe and } \\
\text { supportive workplace environments and policies as well as clinical ethics support) }\end{array}$ \\
\hline 3 Individual liberty & $\begin{array}{l}\text { Respect for clinicians' liberty and personal and professional autonomy means respecting and including their } \\
\text { contributions to strategies which support their own health }\end{array}$ \\
\hline 4 Privacy & $\begin{array}{l}\text { Clinicians have a right to privacy when accessing well-being services to build trust and to protect them from } \\
\text { stigmatisation for accessing services }\end{array}$ \\
\hline 5 Proportionality & $\begin{array}{l}\text { Rosters and workplace systems and policies developed for the delivery of care to patients, should be guided by } \\
\text { considering whether and how they are proportionate to burdens (physical and psychological) they impose on } \\
\text { clinicians }\end{array}$ \\
\hline 6 Reciprocity & $\begin{array}{l}\text { Where clinicians have a disproportionate burden in protecting the public, steps should be taken to reciprocate } \\
\text { (to give back or ease the burden in other ways) }\end{array}$ \\
\hline 7 Equity & $\begin{array}{l}\text { All clinicians have an equal right to have their wellbeing supported. This may mean some clinicians in high- } \\
\text { risk areas require differential modes of support. Extensive consultation with health staff will be required to } \\
\text { develop programs of support and to set equitable working guidelines, policies and expectations }\end{array}$ \\
\hline 8 Solidarity & $\begin{array}{l}\text { Governments, health institutions, individual departments, health teams and clinicians need to acknowledge } \\
\text { their inter-dependence and develop a shared language and set of values about clinician wellbeing alongside } \\
\text { provision of optimal patient care }\end{array}$ \\
\hline 9 Stewardship & $\begin{array}{l}\text { Support for clinicians should be included in as a prominent and visible component of effective stewardship of } \\
\text { health institutions }\end{array}$ \\
\hline 10 Trust & $\begin{array}{l}\text { To build trust, the ethical basis of health administration decisions, including working conditions and expecta- } \\
\text { tions for health staff and for clinical care decisions should be transparent and widely communicated }\end{array}$ \\
\hline
\end{tabular}

\section{What changed for cancer care clinicians?}

The COVID-19 pandemic has fundamentally disrupted cancer care delivery. Key priorities became how to keep patients safe and away from hospitals; maintain social distancing and have appropriate personal protective equipment (PPE) [6]. Within cancer care, reliance on existing best practice guidelines, specialised clinical authority and treatment protocols[6] were, at times, competing rather than parallel considerations. The significantly higher mortality and morbidity risks of COVID-19 infection amongst immunocompromised cancer patients were a constant background concern in every decision [7]. Clinicians had to quickly adjust to practising under different circumstances such as using telehealth instead of face-toface consultations whilst others were redeployed to areas outside of their expertise such as caring for COVID-19 patients. Although these experiences are common to all frontline health staff [8], their impact on cancer care clinicians who may already be at a heightened risk of burnout pre-pandemic [9] represents an important focus.

In Australia, a component of the disruption to cancer care delivery was a period of stillness [10] caused by lockdowns, initially leading to fewer patients attending for routine screening and cancer care. For some clinicians, this resulted in a transient break from delivering care, quickly filled by overwhelming concerns about the potential post-pandemic surge of cancer patients presenting with more advanced disease and needing more complex care [11].

\section{What has been the impact of that change?}

We suggest several significant impacts of these COVID-19 disruptions. The first negative effect is the increased work of providing emotional care to cancer patients, affected by constraints of physical distancing, personal safety concerns, visitor restrictions, state border closures and PPE policies $[7,12]$.

The second and related negative impact is that clinicians have experienced moral distress and anxiety. Adjusting to COVID-19-related restrictions and treatment modifications conflict with ethical ideals of providing targeted, timely and individualised cancer care. Burnout has become more than a profession-based reported statistic and a frequently dismissed element of a doctor's job $[9,13]$. It has become a lived experience for many clinicians $[7,13,14]$. 
The third and potentially positive effect of COVID-19 has been to amplify not only the fragility, humanity and vulnerability of cancer patients but also of their clinicians [15]. The brief period of 'stillness' combined with constraints on delivery of usual care has meant clinicians have experienced a period of being more attuned to their own inner mental and emotional feelings in addition to the ongoing heightened anguish and fear of their patients [10].

Our framing of this experience as a potential positive outcome or high-value opportunity is based on the idea that COVID-19 has acted as a disruptive force opening up a reflective space enabling or perhaps 'forcing' clinicians to fathom their own needs in addition to their patients'. Globally, the pandemic has also brought health administrators and clinicians together to review and ethically justify changes and adjustments to different aspects of healthcare delivery [16]. These COVID-19 impacts for clinicians raise questions including how to address clinicians' experience of trauma and how to leverage heightened awareness of clinician wellbeing as a component of high-quality cancer care in the context of COVID-19 recovery.

\section{How can high-value changes be embedded or enhanced?}

We suggest that embedding staff wellbeing as a high-value change for cancer care delivery post COVID-19 requires clinicians to be clear about what types of support they need and for health leaders to transparently identify and weigh up how they will balance the equally important tasks of supporting clinicians whilst ensuring targets of quality care continue to be achieved. Justifying why one value should take priority over another has been a feature of health ethics during this pandemic[16] and can similarly inform COVID-19 recovery. Emerging models of health leadership [13, 17-19] point to health leaders' complementary duties to ensure patients receive high quality care and staff experience workplaces that protect and promote their wellbeing, enabling them to deliver such care.

Table 1 lists 10 ethical principles (column 1) identified as foundational values which must be considered and then balanced to effectively and transparently steward available resources during and beyond a pandemic [16]. The principles emphasise that actions to protect people from foreseeable harms should be proportionate to the harm rather than unnecessarily restrict autonomy and privacy and should work to promote solidarity and trust amongst those affected. This same list of guiding principles is relevant to health administrators, health funders and clinical leaders in guiding their approaches to balancing care for patients and ensuring clinicians are able to thrive in their workplace (column 2).

\section{Conclusion}

As a disruptive force, COVID-19 has catalysed rapid changes to clinical norms and treatment paradigms in the cancer care context. It has also enforced a period of introspection, self-protection and reflection about the scope and limits of caring for others [20]. This in turn has triggered new perspectives and solutions such as shifting to care underpinned by public health ethical values including that clinicians work to balance competing demands of individual and population health and safety. This experience and ethical framework offer a high-value opportunity to health leaders and clinicians themselves, to similarly review and define (in practical and concrete terms) how they will balance and sustain the dual priorities of promoting clinician well-being and high-quality care for patients as we emerge from the pandemic.

Author contributions All authors whose names appear on the submission have:

1 Made substantial contributions to the conception or design of the work; or the acquisition, analysis, or interpretation of data; or the creation of new software used in the work

2 Drafted the work or revised it critically for important intellectual content

3 Approved the version to be published

4 Agree to be accountable for all aspects of the work in ensuring that questions related to the accuracy or integrity of any part of the work are appropriately investigated and resolved

Availability of data and material (data transparency) Not applicable.

Code availability (software application or custom code) Not applicable.

\section{Declarations}

Ethics approval Not applicable

Consent to participate Not applicable.

Consent for publication Not applicable.

Conflict of interest The authors declare no competing interests.

\section{References}

1. Underhill C, Parente P, McArthur G, Haydon A, McLachlan SA, Wong ZW et al (2020) Towards new models of cancer care in Australia: lessons from Victoria's response to the COVID-19 pandemic. Intern Med J 50(10):1282-1285. https://doi.org/10. 1111/imj. 15012

2. Wong ZW, Cross HL (2020) Telehealth in cancer care during the COVID-19 pandemic. Med J Aust 213(5):237. https://doi. org/10.5694/mja2.50740 
3. Addeo A, Albiges L, Ascierto PA, Banerjee S, Barlesi F, Caldas C, Cardoso F et al (2020) Managing cancer patients during the COVID-19 pandemic: an ESMO Multidisciplinary Expert Consensus. Ann Oncol 31(10):1320-1335. https://doi.org/10. 1016/j.annonc.2020.07.010

4. Cancer Australia (2020) COVID-19 recovery: implications for cancer care, Cancer Australia. Surry Hills, NSW: Cancer Australia; https://www.canceraustralia.gov.au/affected-cancer/infor mation-about-cancer-and-covid-19/covid-19-recovery-implicatio ns-cancer-care. Accessed 8.6.21

5. Victorian COVID-19 Cancer Network I VCCC Alliance (viccompcancerctr.org.au) Accessed 17.9.21

6. Bart NK, Kearney K, Macdonald PS (2020) Put on your own oxygen mask before helping others: mitigating healthcare worker risk from COVID-19. Intern Med J 50(7):891. https://doi.org/10. $1111 /$ imj. 14897

7. Mayor S (2020) COVID-19: impact on cancer workforce and delivery of care. Lancet Oncol 21(5):633. https://doi.org/10.1016/ S1470-2045(20)30240-0

8. Holton S, Wynter K, Trueman M, Bruce S, Sweeney S, Crowe $S$ et al (2020) Psychological well-being of Australian hospital clinical staff during the COVID-19 pandemic. Aust Health Rev 45(3):297-305. https://doi.org/10.1071/AH20203

9. Shanafelt T, Dyrbye L (2012) Oncologist burnout: causes, consequences, and responses. J Clin Oncol 30(11):1235-1241. https:// doi.org/10.1111/joim. 12752

10. Snaith J, Greenfield J (2020) COVID-19: it's changed us. Intern Med J 50:1162-1163. https://doi.org/10.1111/imj.14968

11. Marvelde L, Wolfe R, McArthur G, Blake L, Evans S (2021) Decline in cancer pathology notifications during the 2020 COVID19-related restrictions in Victoria. Med J Aust 214(6):281-283. https://doi.org/10.5694/mja2.50968

12. McDougall RJ, Gillam L, Ko D, Holmes I, Delany C (2021) Balancing health worker well-being and duty to care: an ethical approach to staff safety in COVID-19 and beyond. J Med Ethics 47(5):318-323. https://doi.org/10.1136/medethics-2020-106557

13. Shapiro J, McDonald TB (2020) Supporting clinicians during COVID-19 and beyond-learning from past failures and envisioning new strategies. N Engl J Med 383(27):e142. https:// doi.org/10.1056/NEJMp2024834

14. Delany C, Benhamu J, McDougall R, Ko D, Jones H, Mileshkin L, Largey G, Clinch A, Heynemann S (2021) Supporting cancer care clinicians to 'hold'their patients during and beyond the COVID19 pandemic: a role for reflective ethics discussions. Intern Med J 51(7):1143-1145

15. Young AM, Ashbury FD, Schapira L, Scotté F, Ripamonti CI, Olver IN (2020) Uncertainty upon uncertainty: supportive care for cancer and COVID-19. Support Care Cancer 28(9):4001. https:// doi.org/10.1007/s00520-020-05604-9

16. Thompson AK, Faith K, Gibson JL, Upshur RE (2006) Pandemic influenza preparedness: an ethical framework to guide decisionmaking. BMC Med Ethics 7(1):1-11. https://doi.org/10.1186/ 1472-6939-7-12

17. Greenberg N, Tracy D (2020) What healthcare leaders need to do to protect the psychological well-being of frontline staff in the COVID-19 pandemic. BMJ Leader 4:101-102. https://doi.org/10. 1136/leader-2020-000273

18. Shanafelt T, Trockel M, Rodriguez A, Logan D (2020) Wellnesscentered leadership: equipping health care leaders to cultivate physician well-being and professional fulfillment. Acad Med 96(5):641. https://doi.org/10.1097/ACM.0000000000003907

19. Pollock A, Campbell P, Cheyne J, Cowie J, Davis B, McCallum J et al (2020) Interventions to support the resilience and mental health of frontline health and social care professionals during and after a disease outbreak, epidemic or pandemic: a mixed methods systematic review. Cochrane Database Syst Rev 11(11):CD013779. https://doi.org/10.1002/14651858.CD013779

20. Hwang J, Christensen CM (2008) Disruptive innovation in health care delivery: a framework for business-model innovation. Health Aff 27(5):1329-1335. https://doi.org/10.1377/hlthaff.27.5.1329

Publisher's note Springer Nature remains neutral with regard to jurisdictional claims in published maps and institutional affiliations. 